Electrolytic Polishing and Bright Plating of Metals By Dr. S. Wernick. Pp. xv+243. (Lonuon: Alvin Redman, Ltd., 1948.) 30s. net.

$\mathrm{T}$ the author's preface and in the foreword by Dr. I U. R. Evans, great stress is laid on the commercial value of a brightly finished metal article, be it a piece of a machine or merely a luxury knick-knack. In the foreword it is further pointed out that there is a great practical utility in smoothness, and the examples of reflectors and bearings are quoted; but it is surprising that he does not mention the fact that electrolytic polishing seems to secure a measure of greater resistance to the normal tarnishing of metal surfaces. Except for a fairly full account of the anodic oxidation of aluminium, which is a rather exceptional case, the author's mention of corrosion is more or less limited to a couple of pages (146 and 147) in the chapter on carbon steel. Thus, when one considers the enormous sums of money that are annually expended in combating corrosion, it is surprising that (according to the author) for most metals the extent of the increased protection afforded by electrolytic polishing is rather uncertain.

It seems that to obtain a bright surface there are two rival processes, electrolytic polishing and the deposition of an inherently bright plate; and Dr. Wernick has written a very detailed account of the two techniques even to the extent of suggesting how the former may be used to reinforce the latter. The special attention devoted to nickel surfaces and the appendix on its bright plating are particularly interesting. Little or no theory is presented, as the exact mechanism of these processes does not appear to be understood; but this book is a wealth of empirical information. As such it will be of great value to the qualified ehemical engineer and, being written simply and in a straightforward style, it can be recommended to manufacturers, works managers, etc., who may not have had any formal chemical training.

\section{Dimple-Based Pottery from Central Kavirondo, Kenya Colony}

By M. D. Leakey, the late W. E. Owen and L. S. B. Leakey. (Curyndon Memorial Museum Occasional Papers, No. 2.) Pp. 43. (Cambridge : Deighton, Bell and Co., 1948.) 5s. net.

STUDENTS of the later stages of African prehistory $S$ will welcome the publication of the detailed analytical study by Mrs. Mary Leakey of the ironage pottery industry discovered by Archdeacon W. E. Owen in the Central Kavirondo of northwestern Kenya. Isolated discoveries of pottery with little, if any, apparent affinity to known cultural groups are too frequently merely stored and their publication held over for further evidence. Since modern and recent domestic pottery in tropical Africa often appears to differ so slightly in the details of shape, ingredients and decoration, it is precisely the exceptional elements, like the occurrence of the impressed dimple in this Kavirondo material and its unusual decorative motifs, that are likely to be of significance to workers in other parts of Africa. The excellent drawings by Mrs. Leakey, supported by eight pages of photographs, and the descriptive analysis will give the reader a very accurate idea of the quality of this important pottery assemblage.

No definite age can be postulated for the dimplebased pottery until the geological significance of Owen's "Bed 5" horizon has been determined. The long-range correlation throughout the equatorial belt of the pluvial phenomena deposited during the last important climatic phase (the Nakuran wet phase of East Africa) presents difficult problems which may well eventually be solved by the type of evidence described in this paper. Recent discoveries in northern Nigeria of a pottery culture, associated with late neolithic and early iron-age material, in sealed deposits of a widespread and persistent type invite a very tentative equation with similar deposits (Nakuran) in East Africa, and emphasize the importance of the early publication of in situ cultural material throughout the continent.

Bernard Fagg

\section{Gall Midges of Economic Importance}

By Dr. H. F. Barnes. Vol. 3 : Gall Midges of Fruit. (Agricultural and Horticultural Series.) Pp. 184+ 9 plates. (London: Crosby Lockwood and Son, Ltd., 1948.) 15s. net.

D. BARNES is a tireless investigator with an extensive output of original papers to his credit. $\mathrm{He}$ is, furthermore, a world authority on the Cecidomyidæ or gall midges and, therefore, the proper person to write a book of this kind. It forms the third of a projected series of volumes which he is to write on gall midges of economic importance. As planned, the series will run into eight volumes; the last volume is also to contain a general index to the whole series.

The present volume, like its two predecessors, provides entomologists with well-documented accounts of all that is known about certain kinds of gall midges-in this case those affecting fruit. Much of Dr. Barnes' own work is incorporated in its pages, and he surveys the subject in a thoroughly comprehensive manner, since all known gall midges affecting fruit in different parts of the world are included. A book of this kind, written in a terse but clear style, is invaluable to the horticulturist, the advisory officer and, in fact, to entomologists of all persuasions whether economic, biological or taxonomic in outlook. The long and complete literature list at the end of the book adds greatly to its value as an authoritative work and will mark it out as a standard source for future reference. The author is to be congratulated on his effort, and we wish him every success in completing the task before him.

$$
\text { A. D. I. }
$$

\section{Practical Zoological Illustrations}

Invertebrates. By W. S. Bullough. 32 cards, $14 \frac{1}{2}$ in. $\times 9 \frac{8}{4}$ in. (London : Macmillan and Co., Ltd., 1948.) 15s. net.

THESE cards, illustrating the structure of in1 vertebrates, are on the same lines as the vertebrate series by Lockyer and Crofts. Selected types from the protozoa, cœlenterates, flatworms, roundworms, annelids, crustacea, insects and molluses have been chosen, and a few figures of Amphioxus appended. The drawings are clear and bold, the directions concise, and the notes on the culture of some of the organisms should prove useful. But the set is mory suited to the school than to the university, being neither accurate enough nor full enough for first-year university students, who would discover errors in many of the figures, for example, in the leg of the cockroach, the head of Nereis and the gills of Amphioxus, and who would neod sections as well as dissections of their types.

The printing and production are excellent. 